\title{
Spatio-temporal variability in glacier melt contribution in Bhagirathi river discharge in the headwater region of Himalaya
}

Suneel Kumar Joshi (Research Scientist C),

Suhas D. Khobragade and Sudhir Kumar

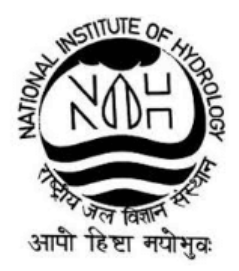

National Institute of Hydrology, Roorkee, Uttarakhand, India

Session: Water Resources Management and the Ecosphere Resilience and Adaptation $5^{\text {th }}$ International Electronic Conference on Water Sciences 


\section{Upper Ganga basin up to Rishikesh}

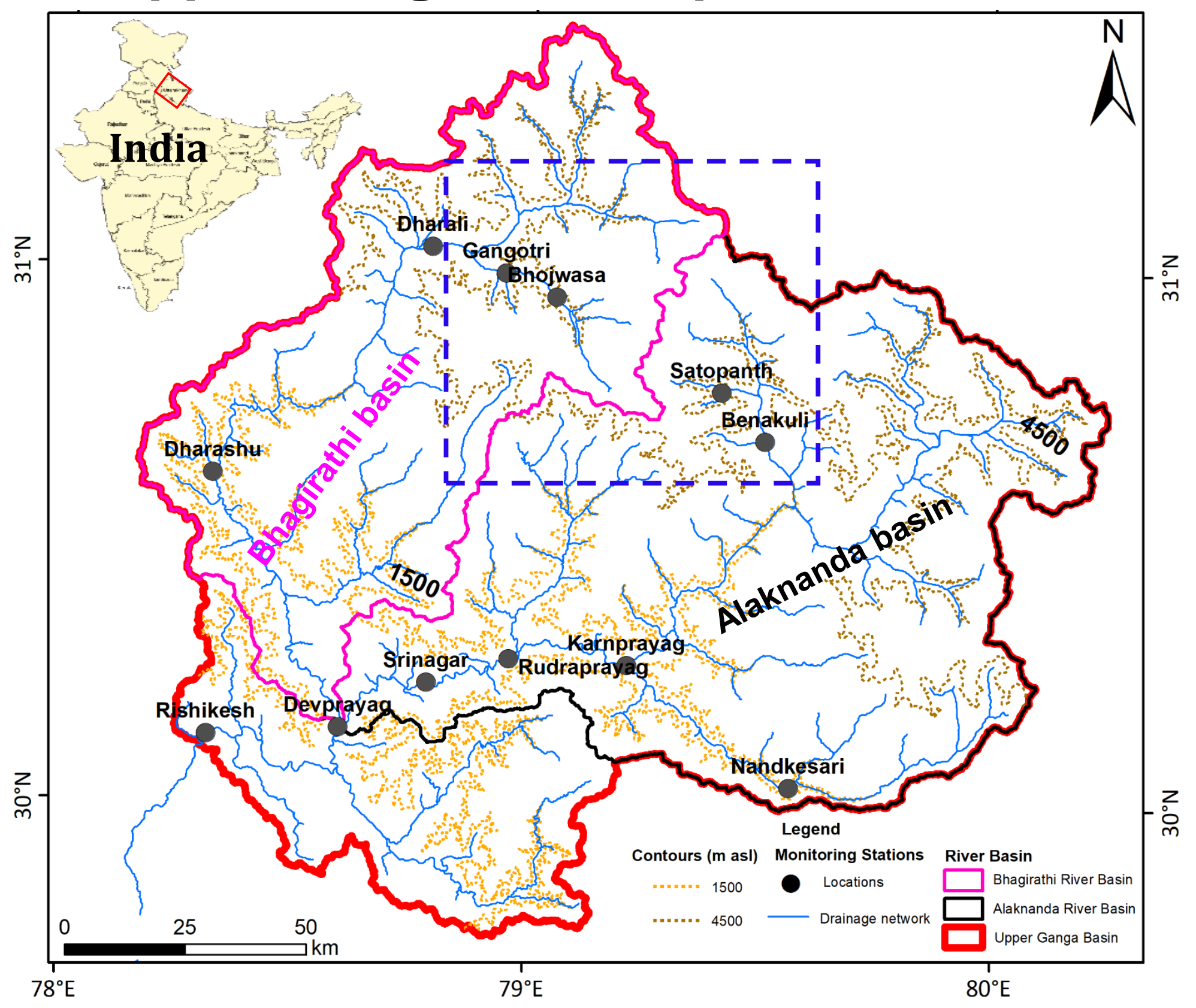




\section{Study area: Gangotri glacier}

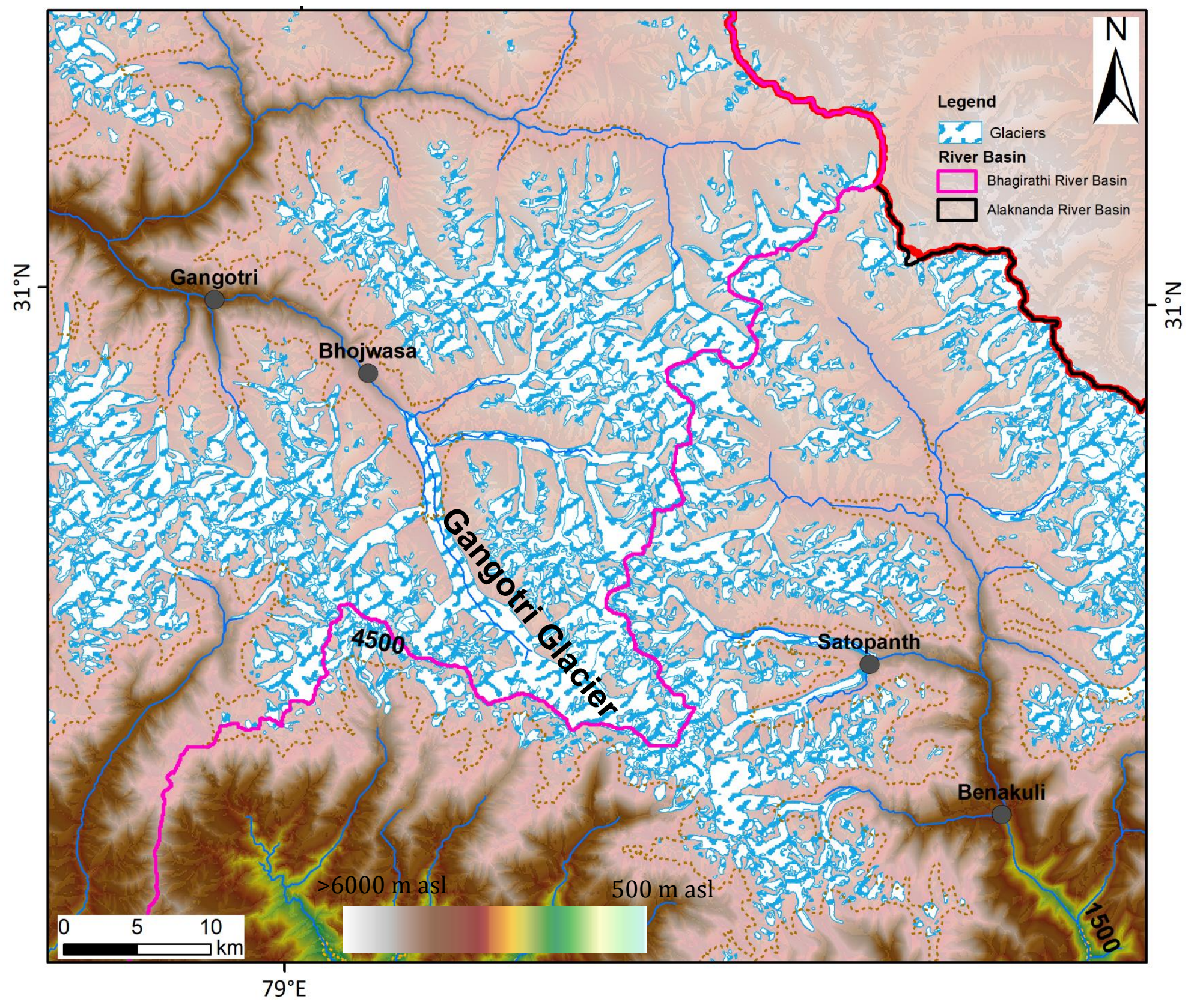




\section{Approach}

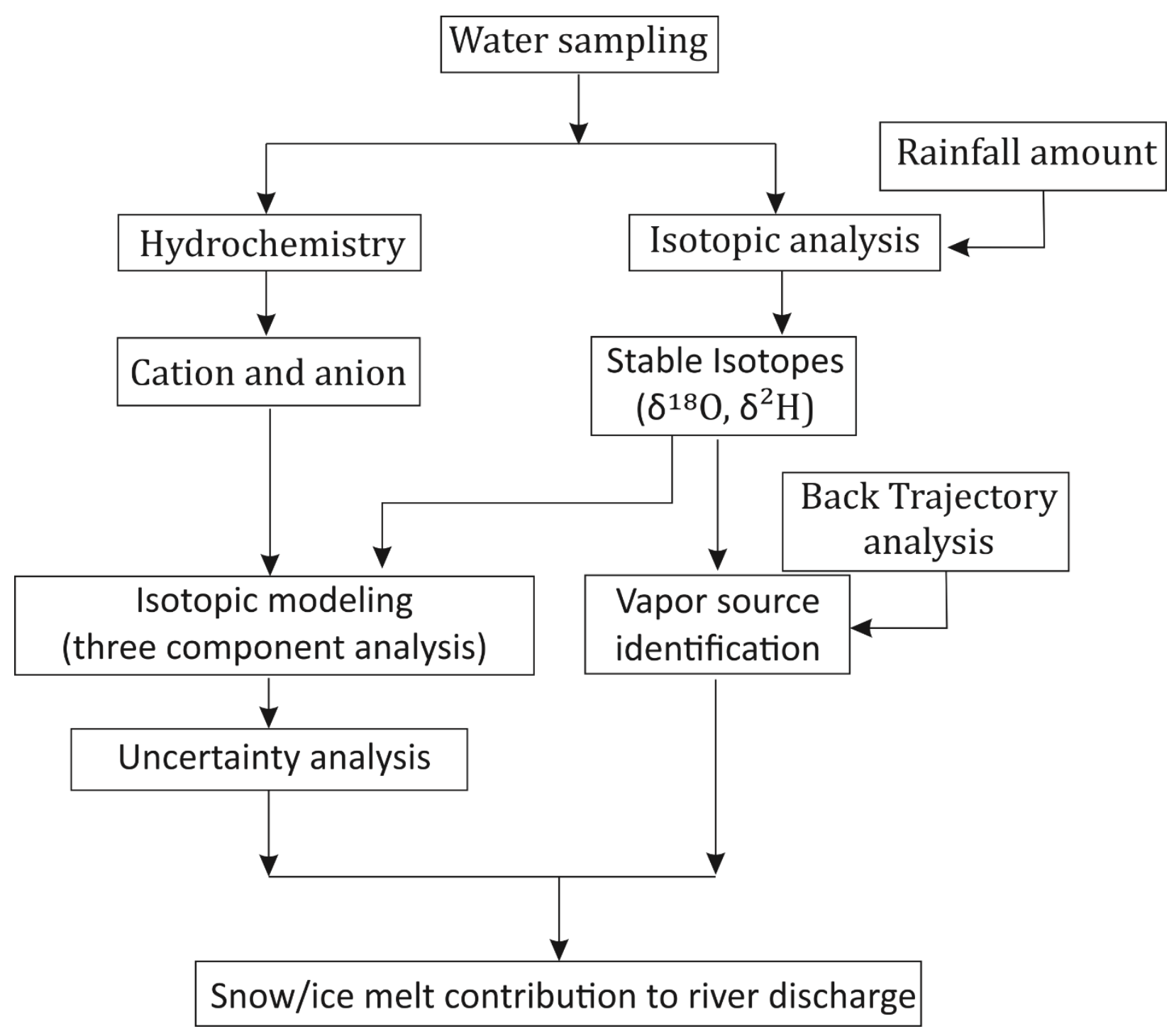




\section{Annual Average Rainfall (mm)}

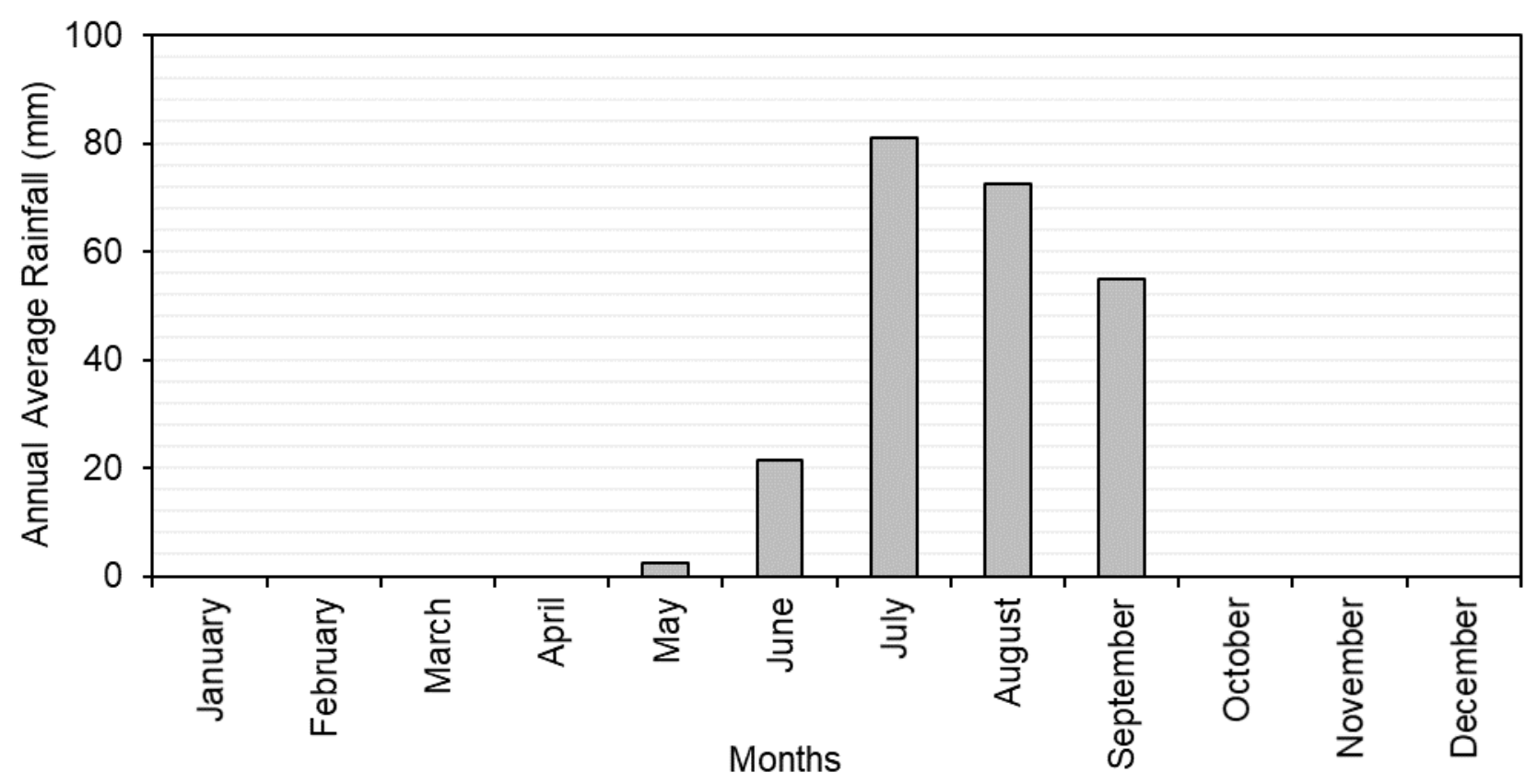




\section{Temporal variation of $\delta^{18} \mathrm{O}$ and rainfall amount}

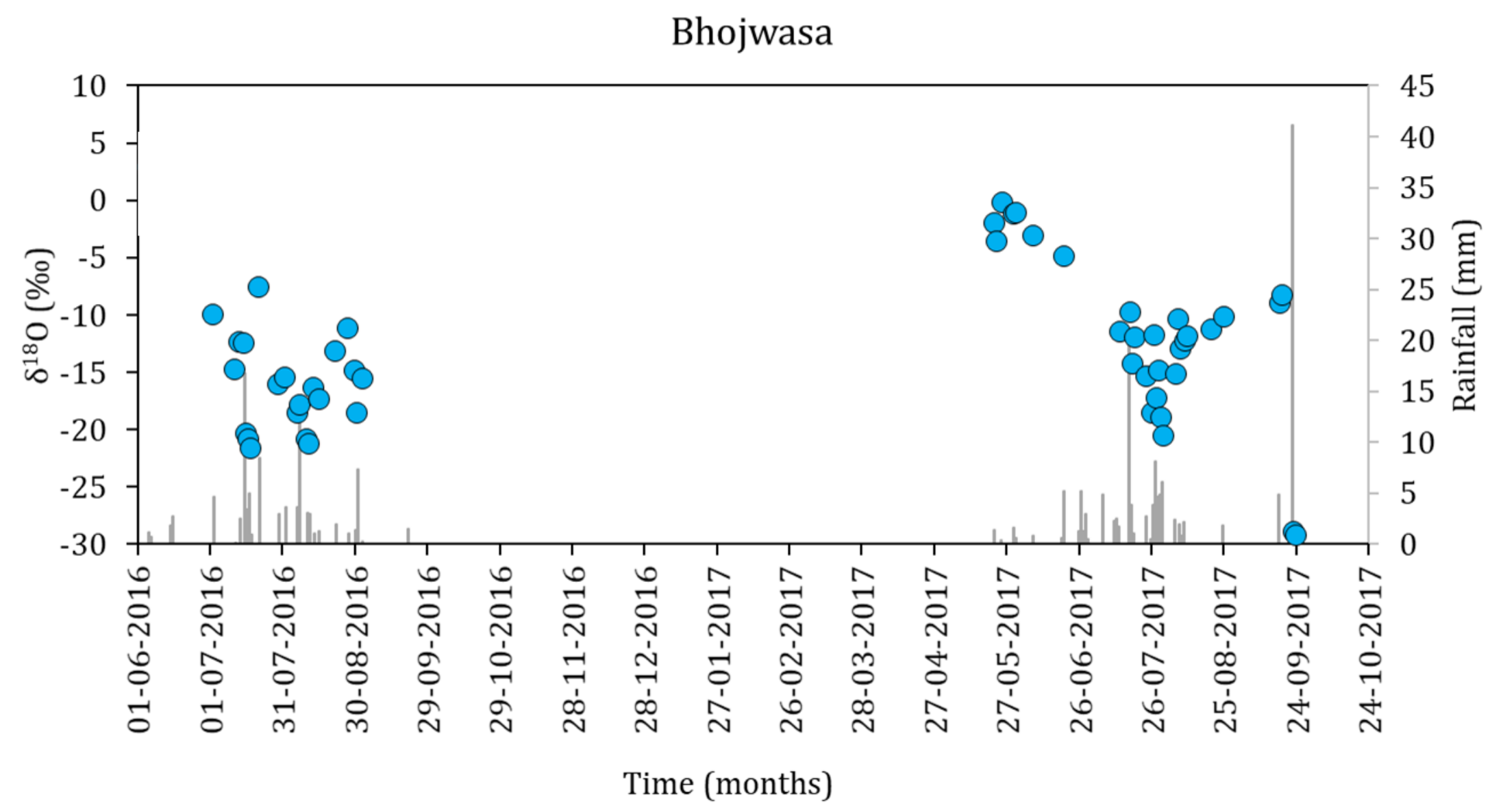




\section{Rainfall amount vs. $\delta^{18} \mathrm{O}$}

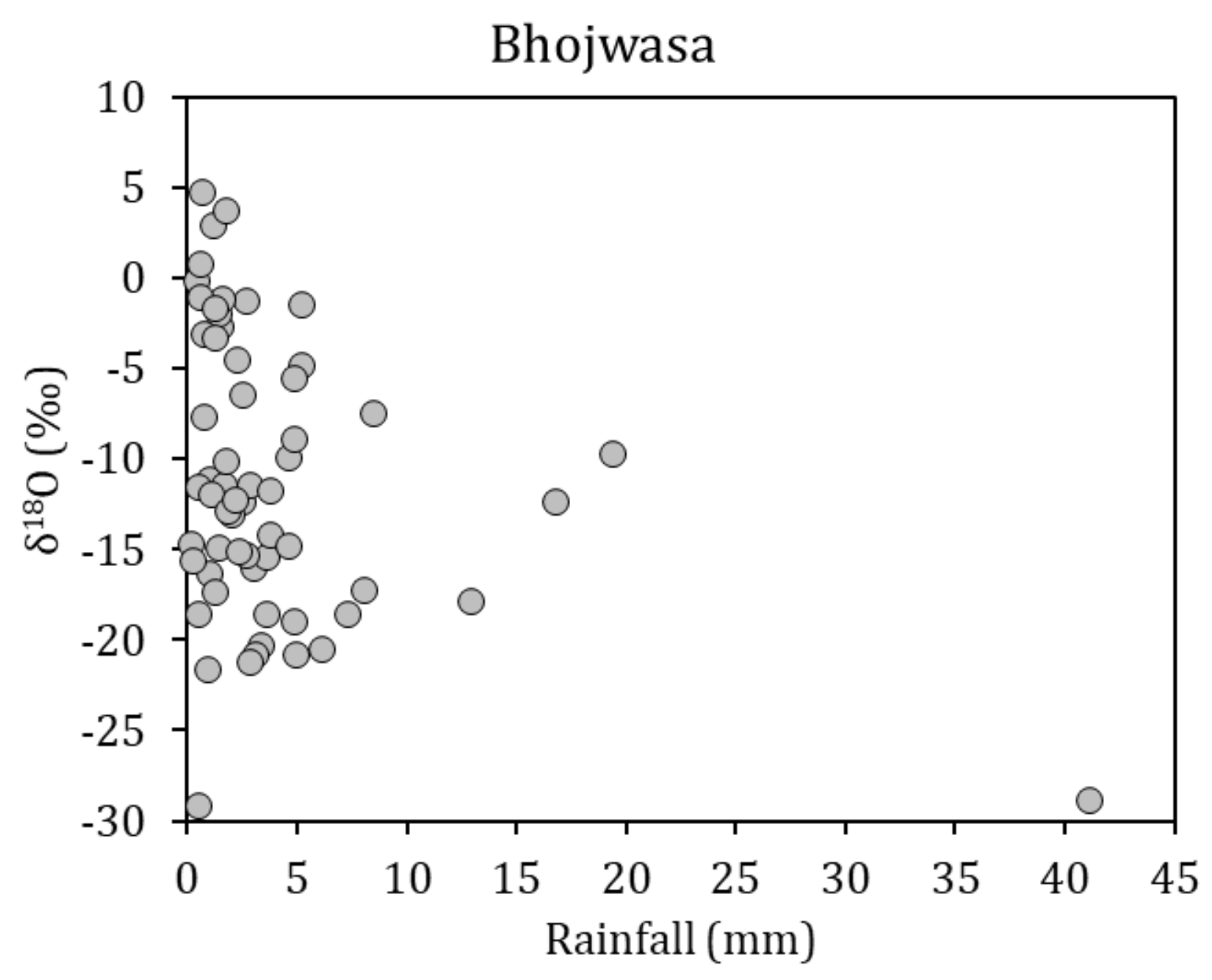




\section{Moisture source for precipitation}
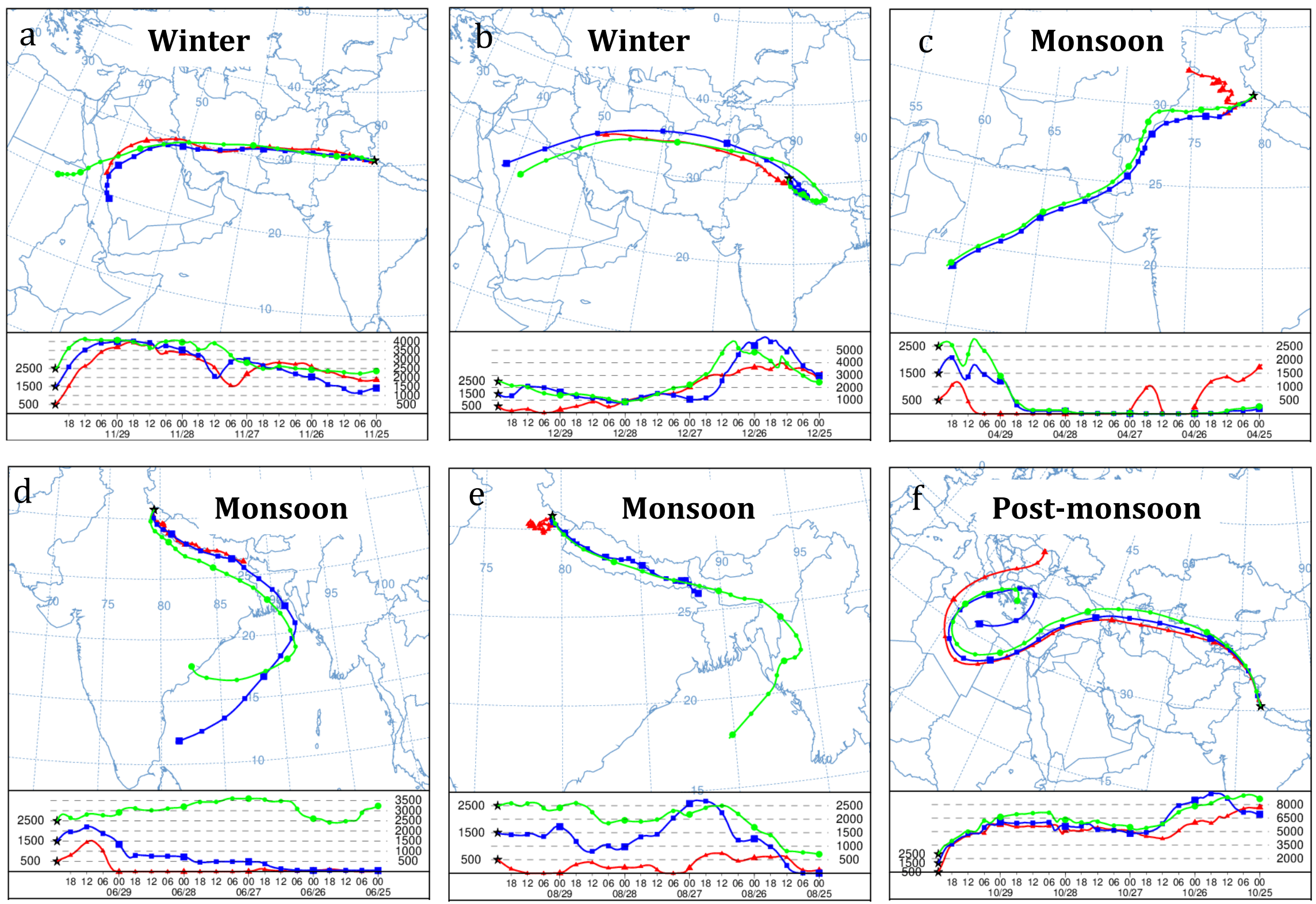


\section{Isotopic composition of rainfall at Bhojwasa}

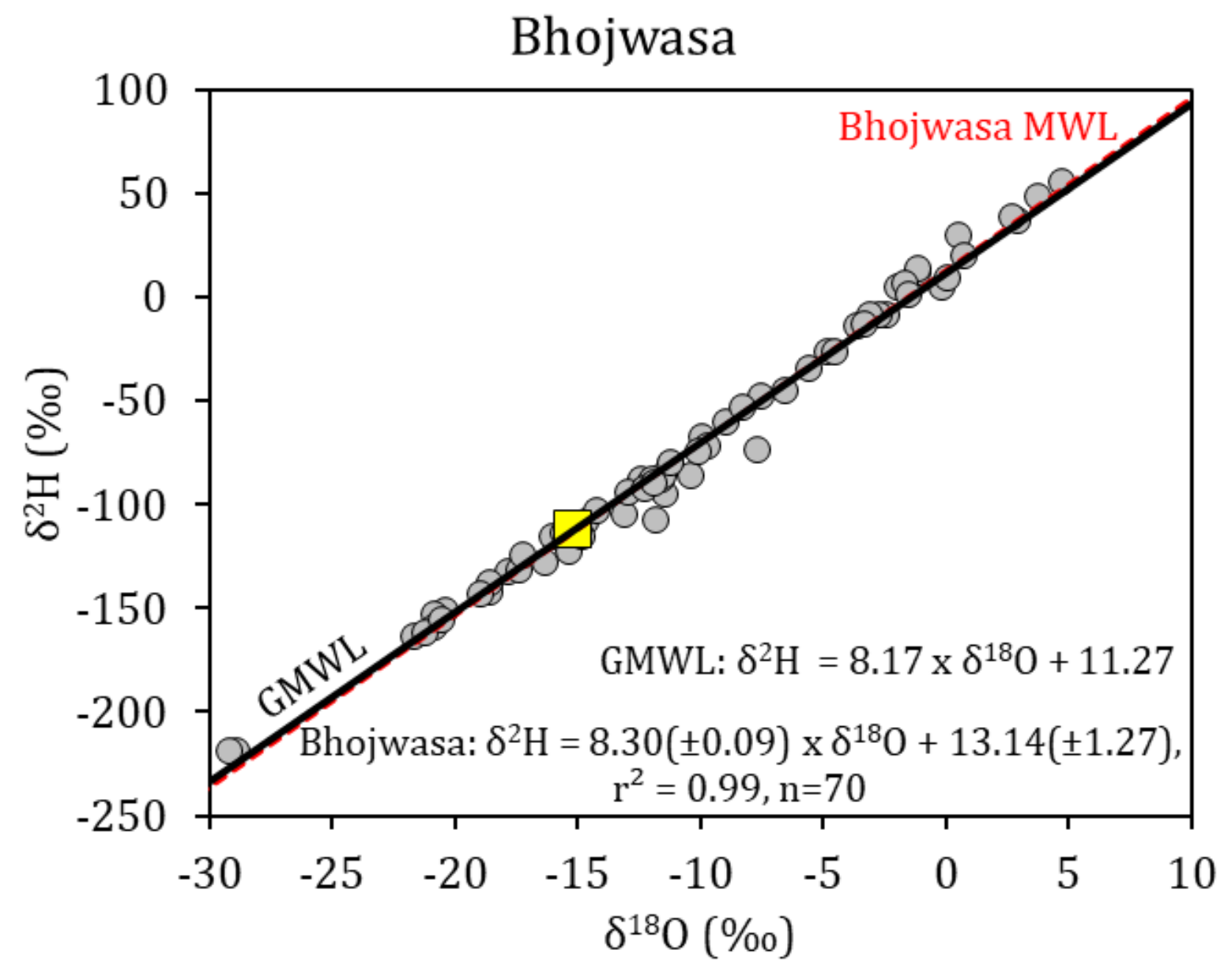




\section{End-member mixing diagram}

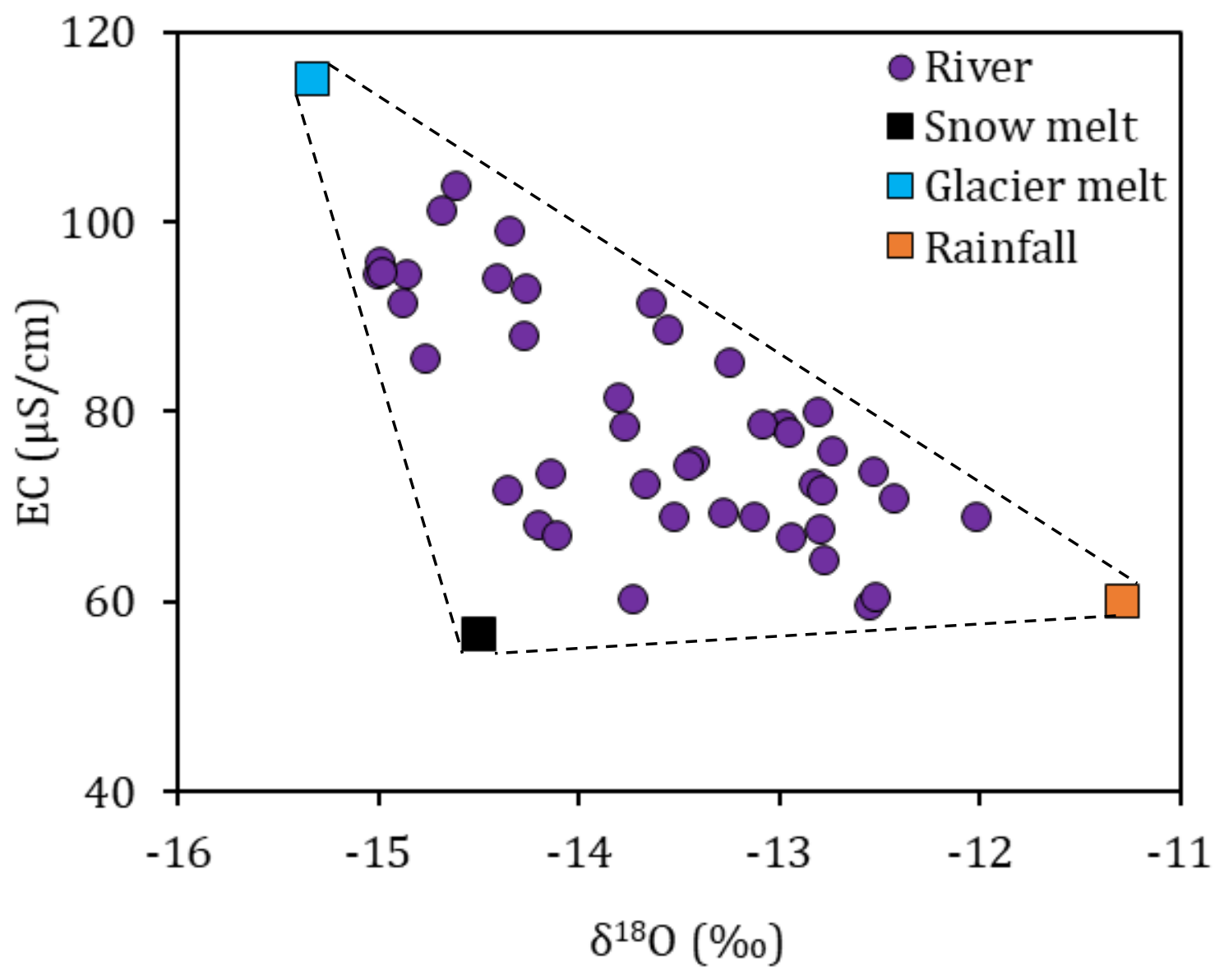




\section{Relative contribution at Bhojwasa}
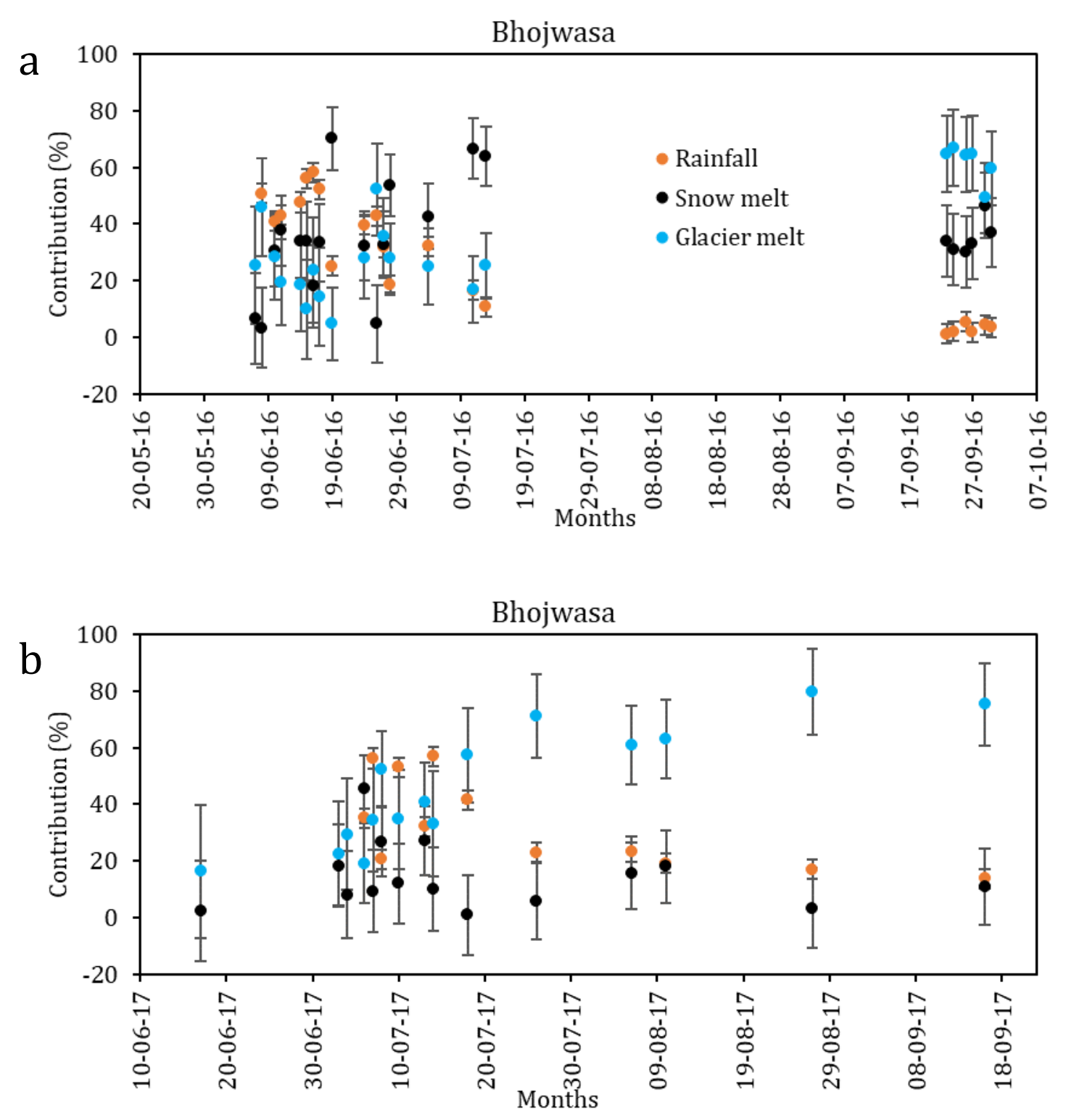


\section{Thank you. . .}



